\title{
NOTAS DE BIBLIOGRAFIA E CRÍTICA
}

DR. EURICO BACK E DR. GERALDO MATTOS - LINGÜISTICA CONSTRUTURAL - separata do Anuário "Humanitas", n. 11,1968 , da p. 45 à 75 , da Fac. de Filosofia, Ciências e Lêtras da Universidade Católica do Paranó.

A obro em aprêço tem por autores dois estudiosos da lingüística moderna, a qual se dedica, como especialidade, oos problemas sincrónicos. Para esta publicação, que merece de nossa parte francos encômios, dados os conhecimentos e a seriedade com que se apresento, a tarefo foi assim repartida: pesquisa ambos os autores, e redação - dr. Eurico Bock. Ambos são docentes-livres de nossa Faculdade de Filosofia: Eurico Back, de Lingüística, e Geraldo Mattos, de Português, e estão igualmente à frente dessas disciplinas na Faculdade de Filosofia, Ciêncios e Lêtras da Universidade Católica do Paraná.

O prof. Eurico Back, além de valiosos estudos no anuório "Humanitas", é 0 autor de Fonêmica Diacrônica Latino-Portuguêsa (tese), Curitiba, 1964, Análise Estrutural, Curitibo, 1967, Roteiro de Redação Óficial (Publicaçāo do Departamento Estadual do Serviço Públicol, Editôro F. T. D., S.A., S. Paulo, s/d. E oo prof. Geraldo Mattos pertencem, entre várias colaborações lingüisticas, 0 Cancioneiro do Clérigo Ayras Nunes (tese) Curitiba, 1962, Técnica de Análise Sintático, Curitiba, 1966, Curso de Lingua Atual, obra didática, e, recentemente, Estilística da Lingua Portuguêsa - Escola Construtural, Edição da Sociedade Paranoense de Estudos de Lingua e Literatura, Curitiba, 1969.

A Lingüística Construtural, obra de colaboração, pretende descrever cientificamente os linguas ( $p .45$ ) de modo global (1), que é mais do que o referente a estruturas, por isto a denominação de construtural, novidade.

A obra nõo é muito clara, talvez por apresentar-se demasiadamente resumida. Parece reservada aos especialistas, pois achamos improvável que tenha êxito satisfatório entre os principiantes, embora defina os têrmos técnicos, vários dos quais com nova conceituação. Ela deverio ser aclarada, a cada passo, com exemplos, que os há, mos poucoe.

$\mathrm{Na}$ Conclusõo (p. 74-75), "o que distingue, dizem os $A A$., $\circ$ que distingue a Lingüística Construtural de outras correntes da Lingüistica Moderna" é o seguinte: I. "A conceituação nítida de estilo e Estilistica". II. "A inclusão dos estudos estilísticos, dos estudos semânticos, dos estudos fonéticos e do léxico na Lingüistica". IIl. "O estudo dos significantes (lexicais e acústicos) sem embaralhar com a Semôntica e sem apelar para o significado, por anticientífico". IV. "O aproveitamento racional dos conceitos de sistema e norma (estabelecidos por outros lingüistas) na Lingüistica Sincrônica e Diacrônica". $V$. "O reconhecimento dos fatôres prosódicos em qualquer nível da série sónica e a conseqüente inclusão da silaba e do seu alinhamento, nos estudos da Lingüisti$\mathrm{co}^{\prime}$. VI. "O conceito de unidade (acústica e lexical), colocando morfema e vocábulo nos seus devidos lugares". VII. "A conceituação de Lingüística Diacrônico, de evolução fonológica, de evolução vocabular". VIII. "O conceito de

(1) "É indispensável que se levem em conta todos os dados e que a descrição seja adequada a todos os elementos que estão em jôgo. Náo bosta dizer a verdade; é preciso dizer tôda a verdade" ( $p$. 45). 
construtura e o reconhecimento dos diversos tipos de articulaçōes (coesāo, alinhamento, arranjo), e por conseguinte, a delimitação dos diversos niveis". IX. "O trotomento uniforme e coerente de todos os fatos lingüisticos, sobretudo c análise do periodo".

Não sōo novidades olguns dêsses principios. À definição de Estilistica per guntamos: Tudo isso para quê? Esto pergunto nāo teria cabimento se a finalidade da linguagem fòsse tāo só comunicaçāo (p. 45).

Reconhecendo que há quem excluo do Lingüistica os estudos estilísticos, $e$ sem razão, somos, com os AA., pela suo inclusāo, por mais de um respeito. Por outro lado, incluir nela os estudos $s \in$ mànticos, os estudos fonéticos e o léxico é redundôncia. Tais estudos sá membros notos da Lingüistica.

Apresentar os fatos fundamentais da linguagem humano "sem compromisso $\mathrm{com}$ as correntes atuais da Lingüistica ou as nomenclaturas existentes" $\dot{e}$ atitude que se explica tão só pelas dificuldades que se tèm, mormente no Brasil, em estar a par de tôdas as novidades. Haja vista, p. ex., as transformaçōes das gramáticas transformacionais! Mas seria de proveito, mormente para os principiantes (e incluidos, no Brasil, muitos professòres de Lingüistica) que, pelo menos, se comparossem as principois correntes com suas técnicas descritivas. Lembra-me, a propósito, que um dos grandes movimentos que se opuseram ao neogramaticismo, foi a neolingüistica. Pois bem; ao publicar-se, em 1925, o Breviario di Neolinguistica (princípios gerais por $G$. Bertoni, e critérios técnicos por M. G. Bártoli) nāo deixaram os AA. de reservar um opêndice com êste título: "Le differenze essenziali tra it metodo neolinguistico e il neogrammatico". No mesmo ono, Bártoli publicava c Introduzione alla Neolinguistica (Principi, scopi, metodi), e um capitulo bem desenvolvido tratou das diferenças entre as duos escolos.

Quanto à nomenclatura, devemos chomar a atençāo dos colegas construturalistas para a Léxica, "estudo dos significantes". Não forom felizes, nōo tonto porque o têrmo e seus cognatos jó têm internocionalmente um ômbito consogrodo, mas principalmente porque o adjetivo dêle decorrente - lexical - criou a redundancia significante lexical (p. ex., na p. 54).

A leitura da obra nos convidou ainda a mais algumas observações:

Na p. 45: Melhor que "muitos sistemas de comunicação são apenas substitutos do linguogem" serio "todos..."; é óbvio, com exclusão do música, da pin tura.

P. 46: "A linguagem, em nosso trabatho, será linguagem vocal". Nada obstante, há frequientes preocupaçōes com - linguogem eserita.

"Nosso afirmaçāo (2) de que a linguogem é um diálogo..."

$E^{\prime}$ da natureza primordial da linguagem o diálogo, decorrente da finalidade dela, e tal foi reconhecido pela mais remoto ontiguidade.

P. 46: "A Lingüistica. . . nōo se preocupa em estudar as relaçōes entre os sinais... e os objetos". Então como se explica a objetologia, a geolinguística e a neo-etimologia?

P. 47: "Os organismos (o emissor e 0 receptor) sõo entes extralingüisticos $e$ nāo sāo estudados pela Lingüística, nem as suas reações extralingüísticas..."

Como conciliar esta afirmação com a que diz "sendo um elemento da cultura, precisa retratar tóda a cultura, inclusive a si mesma" (p. 47), e o conceito de idioleto e de normo obriga a tomar em consideraçāo o indivíduo e o grupo social extralingüisticamente, pois "como a cultura varia de época a época, de regiäo a regiäo, de closse social a classe social, necessòriamente variom também os elementos de idioma a idiomo, de regiāo a regiōo, de classe social a classe social".

"A soma de conhecimentos varia de pessoo a pessoo: portanto o idioma varia também de indivíduo 0 individuo". ( $P$. 47-48).

P. 48: A lingüistica diacrônica nāo é sòmente "o estudo comparativo de línguas de pelo menos dois momentos sucessivos". Nāo é exclusivamente "a comparação entre duas sincronias, quando a segunda linguo é o resultado da evoluçāo da primeiro". É, sim, também o que a lingüistica tradicional chama com. poração interna ou reconstruçāo interna ou, ainda, filiação (parentesco reto). A lingüístico diacrônica pode ser também

(2) O grifado é nosso. 
referente a duas ou mais linguas aparentadas colateralmente, isto é, tradicionalmente, comparação externa ou simplesmente comparação, "stricto sen$\mathrm{su}^{\prime \prime}$.

Ademais, a lingüística sincrônica pode ser tombém comparativa, visto que podem ser cotejadas duas ou mais línguas de um determinado momento, quer aporentadas, quer não aparentadas. Não basta, portanto, linguiistica comparada, mas distinguir lingüistica comparada diacrônica e lingüistica comparada sincrônica.

P. 52: "As linguas podem possuir sinônimos e homônimos".

Seja qual fôr o conceito de sinônimo e homónimo, é isto realidade em tôdos as línguas. Um estudo especializodo de $\mathrm{S}$. Ullmann não os nega, apesar das suas restrições conceptuais (3).

No p. 56, os AA. nāo tomaram em consideração as vogais que podem formar uma silabo, isto é, p. ex., vogal tonica e vogal átona, ou, em outras palavras, vogal e semivogal.

P. 68: "A ausência de um significante pode ser um sinal". Perante isto, como resolvem os $A A$. o relacionamento com o sinal, uma vez que êste é a soma ou uniōo do significante com o signiticado (p. 46)? A soluçāo só pode ser esta: $A$ ausência de um significante pode ser um significado. E a propósito, convém lembrar o inverso, isto é, pode haver sinais desprovidos de signiticado (assemio, estoglossio).

Parece que há um cochilo tipográfico ou simile na p. $69,3 .^{\circ}$ linha: $\operatorname{mar}=$ e - es.

$\mathrm{Na}$ p. 73 a definição de lingüistica diacrônica não concorda com a definição dada à p. 71. Naquela página, o que se definiu, é diacronia. Não é, pois, exatomente 0 mesmo que lingǘística diacrônica.

Na p. 75, a afirmação - "o estilo é a língua praticada" — parece que nõo se hormoniza com a afirmação da p. 61 - "Quando um elemento do estito fôr adotado pela maioria, passa imediatamente à línguo: realizou-se uma evolução lingüística".

E aqui nos detemos, deixando de la do pontículos de "Iana caprina"...

Fazemos votos tenhamos, dentro em breve, outra edição, verdadeiro breviário ou vademeco, ampliado, bem ilustrado, para que, obedecendo aos seus princí pios, possa oferecer "umo técnica seguro para a análise e a descriçāo científica de línguos".

Náo queremos encerrar as linhas sem antes dar parabéns aos AA., especialmente ao dr. Eurico Bock, nosso ex-aluno na Faculdade Federal, que em boa horo enveredou pelos cominhos da nova lingüistico, que está avassalando o mundo científico das Lêtras, o que honra sobremaneira as nossas Faculdades.

R. F. Mansur Guérios.

$* * *$

ANTENOR NASCENTES - DICIONÁRIO DE SINÔNIMOS - Coleção Brasileira de Filologia Portuguêsa, Livros de Portugal, 384 pp., Rio, 1969.

O infatigável e admirando mestre que é Antenor Nascentes, acaba de nos brindar com mais um dicionório, agora com - Dicionário de Sinônimos, 2. edição, revisada e com ocréscimos.

Lingüista de atividades multiformes, Nascentes está dando agora os últimos retoques tipográticos ao Dicionário Etiinologico da Lingua Portuguêsa - 3.a parte - Exotismos, consoante corta que nos dirigiu em outubro, e nela ainda nos anuncia estar no prelo A Giria Brasileira, $2 .^{\circ}$ edição, cuja $1 .^{a}$ hó muito se acha esgotada.

$\mathrm{Na}$ Introdução, em breves e precisas palavras, faz o A. valiosas consideraçōes acêrca da sinonímia. Se alguma restrição é possível, ela diz respeito ao relacionamento com a etimologia para fazer valer a sua significaçōo. E' verdade que isto dirime certas dúvidas, mas nem sem. pre é recurso aconselhável, pois é sabido que há mudanças nos sentidos através dos tempos.

O problema dos sinônimos parece que se baseia primordialmente na existência ou nõo de equaçōes semânticos perfeitas. O prot. Nascentes admite-a, mas concicionada a áreas geográficas e sociais, isto é, numa regiāo e em outra, numa camada social e em outra.

Ademais, o sentido de uma palavra deve ser deduzido do contexto ou da situaçõo ou de ambos simultâneamente,

(3) Semantic Universals "in" Universals of Language, Combridge, Mass., 1963, p. 182 e p. 186. 
e nào isoladomente. Desde que hajo pos. sibilidode de substituir umo polovro por outra, sem mudança da significação objetivo e do valor afetivo, ambos as polavras são verdadeiros sinônimos. Contudo, na maioria dos casos, é impossive a permuta em todos os aspectos. Hó diferenças cousodas pelo falante e pelas circunstâncias já citadas (meio geográfico e meio social), e mesmo pela natureza fónica dos vocábulos, que pode contribuir para a emotividade. Entre os têrmos técnicos, sim, hó perfeito sinonimio.

Nōo se deve, portonto, definir os sinónimos como duas ou mais palavras dificrentes no forma e com o mesmo sentido, mas como duas ou mais expressões que formam equação semôntica oproximada. E por expressāo enterder-se-á polovra ou locuçāo ou enunciado (frase), admitindo o conceito amplo de sinónimo, o qual nāo é só o de correspondência de classe gramatical, mas tombém de equivalèncio contextual.

Registremos ainda que hó sinónimos momentòneos, ocasionais, que, podendo até ser absurdos, sāo, todovia, compreendidos intuitivamente, graços ao contexto, ò situaçāo ou a qualquer fator lodivinhaçōo, tronsmissōo do pensomento, etc.). P. ex., necessitando alguém de uma caneta, pede a outro, no entanto, por qualquer motivo, um canivete, umo vassoura... E' claro que isso é verifi cóvel sèriomente, inconscientemente, su na linguagem oral, e, conscientemente com propósito humoristico ou burlesco tanto na oral como no escrita.

O Dicionório de Sinônimos que sc anuncia nestas linhas, é rico de verbétes, rico de sinônimos, rico de informaçōes. Freqüentemente se comparom expressōes do Brosil com expressōes de Portugal. Quando a sinonimia se reparte entre expressōes brasileiras, sōo designadas as regiōes ou os Estados. A sua riqueza ainda se reflete nos sinônimos da fauna e da flora, o que nōo tem vez em nenhuma obra símile. Seja exemplo da primeira cugar, cuguardo, leāo-da-américa, onça parda, onça vermelha, puma, suçuarana, isto é, "mamifero do familia Felidae (Felis concolor)", e o informação: "O quarto, o quinto e o sétimo é que são os nomes vulgores". Acrescentemos onça ruivo.

Seja exemplo da segunda flor-da-noite, flor-do-baile, princesa-da-noite, rainho-da-noite, rainha-do-baile, isto é, "planta da familia Cactaceae (Selenicereus pieranthus)".

Algumas notas, contudo, cabem a certos verbêtes: Accougue, pelo que se deduz de Morais, era também "mercado". Em abissinio, etiope juntar abexim. Anúncio é também "reclome, propaganda". Anágua é igualmente do Sul do Brosil, pelo menos do Paraná. Bolchevique (e bolcheviquista) usa-se tombém como sinônimo de comunista. Foi separado o que devio estar num só verbête, isto é, assopsador, bòto, bôto branco, de um lado, e de outro bôto (de aguo doce), peixe-porco. Anexar meigueira (Portugal) a bruxa, feiticeira, maga. A cacoete, sestro, opor tique. Temos lido, e frequientemente, capixaba (espirito-santense) sem qualquer troço de jocosidade. Casaco também usa a mulher. No tempo em que fomos comercionte, em Curitibo, poucas vêzes ouvimos conhecimento; mais freqüentemente guia. No comércio, distingue-se a cinta, que é pora homem, e o cinto para mulher. Em comunhäo, eucaristia, acrescentar Santissimo Sacramento, Santissimo, Santissima Eucaristio, Sacramento do Amor, Pão dos Anjos. Em gatuno, ladrão, larápio, ratoneiro juntar gato, rato, amigo-do-alheio. Acrescentar zinha a garôta, namorada, pequena. Ao lado de guará, lôbo, juntar aguará, como ao lodo de inambu, nambu, aponha-se nhambu, inhambu $e$ inambu. Com 0 restabeiecimento do Estado de Israel, a imprensa criou israelense, que é o cidadoo atual, ai nascido ou naturalizado. A leguleio, rábula deve-se aditar chicaneiro, chicanista, rabulista, pêgas. Escaparate e redoma podem olinhar-se a montra, etc., assim como o oportuguesado vitrina. Parece que no Paraná é mois comum ou tradicional nenê. Está averbado nenê como brasileirismo no edição brasileira de Aulete. Juntar experto a perito, versado, e gelosia a persiana, veneziana. Conforme a doutrina católica, o sacrilégio é a "profanação das coisas sontas ou consagradas a Deus, ou 0 violação ou mau trato de pessoas ou coisas sagradas, enquanto sagradas" (Pe. J. Lourenço, Dic. da Doutrina Católica).

Nem sempre os sinônimos sāo remetidos, para facilitar a consulto. Assim, p. ex., mercearia só se acha no verbête iniciado por empório, mas näo na lêtra

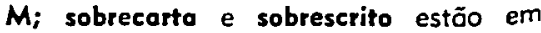


envelope; fuxilar, que é mais conhecido, está, não obstante, no verbête iniciado por espingardear.

Tais são algumas notas despretensiosas que nos proporcionou o rápido perlustrar de suas páginas.

Além das riquezas acenadas nas primeiras linhas desta recensão, o Dicionário de Sinônimos de Antenor Nascentes contém sinonimia de nomes mitológicos e geográficos, de neologismos, de expressōes não só populares, mas também de expressões gíricas, assim como de palavras invariáveis.

\section{R. F. Mansur Guérios.}

$$
\text { * * * * }
$$

ANSELMO MAZURKIEWICZ - DICIONÁRIO dE TERMOS PRÓRIOS E RELATIVOS - Editôra Vozes Ltda., 730 pp., Petrópolis, 1968.

Trata-se de um dicionário especial de muito préstimo para quem quer que seja, desde o cientista até ao charadista ou a qualquer curioso. Serve para tôdas as atividades científicas e não menos paro as atividades literários. Sua estrutura "foi organizada de modo que otendo oo estudioso que busca a palavra para a idéia". E "o seu manuseio é tāo fácil quanto o de dicionários comuns de verbêtes ordenados alfabèticamente".

Trabalho dessa natureza, em riquissima apresentação, encadernado com finíssimo gôsto, é digno de muitos encômios, quer por trazer definições (parece-nos que obra dêsse gênero poderia dispensá-los, como fazem os dicionários analógicos), quer pelo conteúdo bem provido em títulos (p. ex., biblia, concilios ecumênicos, forma, inflamação, medicina, navio, teatro, tecido, vaso, vestuário), quer pelas dificuldades de tôda sorte, e dada a sua descomunal dimensōo sob qualquer aspecto, é claro que vem repleto de falhas, as quais, todavia, devem ser tolerados. $E^{\prime}$ evidente que não há dicionário completo, mas cada novo edição pode e deve ser ampliada.

Pelo que pudemos perlustrar, ainda que perfunctòriamente, eis alguns senões:

Não devia haver, assim pensamos, ti tulo, p. ex., para água benta, aguilhāo (mesmo para remissão), bucha, céu-dabôca, etc.

Deviam ser postergados as formas evidentemente estrangeiras, como la- sagna (sob o título alimento), como dikérion (sob o título liturgia), etc. $E^{\prime}$ claro que o A. deveria aportuguesá-las. Hó, sim, lasanho, e por que não diquério?

De modo nenhum tem cabimento $O$ título neologismos. Há uma quantidade considerável de neologismos que lá não foram agasalhados, e, ademais, I outros, muitíssimos, que estão incluidc nos vários títulos.

No cabeçalho adivinhação, por que defini-la com negrito: "Suposto arte....", $e$ por que dois títulos para o mesmo assunto?

S. v. alimento não consta macarrão, nhoque, espaguete, talharim, massa, etc. $O$ que consta sob o titulo maçonaria é quase nada. Devia o $A$. incluir o cabeçalho genérico passamanaria, que, todavia, consta em fita. E anexar ali grega, renda, guipura (= guipir), nhanduti, etc.

Em clero estão ausentes clero secular e clero regular, assim como religioso, religiosa, substantivos, bispo auxiliar, bispo coadjutor, bispo residente, bispo titular, vigário episcopal.

No título cornaval faltom xé-pereira, serpentina, confete, bisnaga, lança-perfume, colombina, mascarado.

Introduzir o título cancro e subtítulo em côncer.

Em cócegas falta cafuné, em astronomia elongação, em música piano. Em cinema devio haver remissōo para filme e em filme para cinema.

Em raça falta moçárabe, monogênese. Em povo ou em raça incluir etnia. $\mathrm{Em}$ pais remeter a poyo, indio. Em caminho estão ousentes rodovia, rodoviário, estrada de rodagem, auto-estrada, via. Em estrada de ferro nāo foram considerados o dormente, a sulipa.

Em fruto a falta é sumamente enorme. A lista dos indios é grande, parece completa, mas não é. Por que o $\mathrm{A}$. não definiu rouxinol?

O A. dá os cabeçalhos Astronomia, Botônica, Geografia, etc. , mas por que não Lingüística, pois isto inclui a língua e a gramática.

Há definições que hoje se consideram erradas ou incompletas, e nisto não estó "perfeitamente atualizado" ○ Pequeno Dicionário da Língua Portuguêsa, que serviu de base principal oo Sr. Anselmo Mazurkiewicz. Para prová-los bastem as definiçōes de fonética, fonologia, 
haplologia, lingüistica, locativo, morfologia, e, em som, fonema.

$\mathrm{Na}$ "Relação de algumas obras consultadas" parece-nos que um bom número delas poderia ser dispensado. Se féz uso do Dicionário Litúrgico de $\mathrm{Fr}$. Bosilio Röwer, por que não manuseou os vários léxicos especializodos, como o Dicionório Gromotical Port. de Silvio Elia (Ed. Globo), o Dic. de Filologia \& Gramática de J. Mattoso Còmara, o Dic. Musical de Fr. Pedro Sinzig, o Dic. Je Biologia de C. de Melo-Leitāo, o Dic. de Tèrmos Médicos de P. A. Pinto, o Dic. de Belas Artes de Regina $M$. Real, 0 Peq. Vocabulária da Lingua Filosófica de A. Cuvillier, o Dic. de Psicologia de Henri Piéron, o Dic. Económico e Financeiro de L. Souso Gomes, o Dicionário de Botânica de J. Angely, etc.

No rápido perlustrar do obra, nõo tivemos oportunidade de encontrar verbêtes com os diples $>\mathrm{e}<$, os quais, segundo nos parece, não tém cabimento em dicionário dèste gènero.

Tudo o que acabamos de ofirmar nōo é para menosprezar o trabalho ingente do A.; é leal colaboraçōo, e repetimos o que disse dèle o presidente do Academio Brasileiro de Lètros, Austregésilo de Ataide: "Trato-se de um dicionário de grande utilidade". E acrescentomos que èle vai servir de modo especial para os lingüistos, principalmente pelo que tange aos diversos campos semánticos.

\section{R. F. Mansur Guérios. $* * *$}

GEOFFREY N. LEECH - ENGLISH IN ADVERTISING - A LINGUISTIC STUDY OF ADVERTISING IN GREAT BRITAIN - English Language Series, XIV, 210 pp., General Editor Randolph Quirk, Longmans, Londres, 1966.

E' a segunda obra de uma série referente ò língua inglèsa, de autoria de G. N. Leech, leitor de Inglès no Colégio Universitório de Londres, onde é tombém secretário assistente do Centro de Pesquisas da Comunicoçōo, e ainda especialista em Semántica. Seus estudos têm sido publicados em Studia Neophilologica, A Review of English Literature e New Society.

O livro que nos interesso aqui, é muito curioso não só pelo que trato - linguagem dos anúncios, do propoganda comercial da Grā Bretanha, na atualidade - mos tombém pelo modo pelo qual trata, e sob todos os aspectos.

Nōo é uma obra exclusivamente para oquêles que já têm certa bose de Lingüistica; é, sim, tombém para o público em geral. Todavia, como diz o prefácio, "as an exercise in linguistic description, it obviously connot entirely do without technical linguistic vocabulary; and some words and phrases necessarily been adopted as additional technical terms for the specific purpose of this onalysis."

O inglès dos anúncios tem despertado a atenção de lingüistas há muitos anos, e a maioria dos trabalhos sôbre 0 idioma inglès tem sustentado várias afirmaçōes gerais acêrco do assunto. Poucos especiolistas tèm, contudo, feito progressos, como é o caso do A., o qual, mediante sólido corpo de experiêncios ? pesquisas, por vários anos, chegou a percucientes estudos respeitante à linguagem dos onúncios ou, melhor, da $p \in$ suasōo comercial principalmente através da televisóo, e, mediante profundo conhecimento das atuois teorias linguiisticos, assinala o lugar competente dessas pesquisas dentro da Estilística geral.

O A. compara diferentes estilos de anúncios, assim como coteja a linguagem dos anúncios em geral com outras modalidades de inglès. Considera como traços típicos dos seus onúncios a limitaçco do repertório lingüístico e a sua reperiçāo, estuda os desvios dêsse ospecto convencional. Além do mais, o $A$. considera a história da linguagem da propaganda comercial, dos anúncios, $E$ dos expedientes poéticos e retóricos. $M$ sim, a obra é importante contribuiçāo para o estudo dos ospectos lingüísticos đo estilo, nāo só para os que desejam ter connecimento do inglès nesse campo de atividade, mas também para os que se interessam por outros suas modalidades.

Alguns conteúdos da obra:

Generalidades: Os anúncios interessam ao sociólogo, ao psicólogo, ao lingüisto, assim como aos próprios propagandistas e cos demais profissionais.

instrumental lingüístico (ortografio, vocabulário, gramático, fonologia, contexto, estrutura, etc.). O inglês dos anúncios e outros modalidades de inglês. Meios de tronsmissōo, e linguagem de 
acôrdo com os produtos ou artigos anunciados. Modalidades do inglês empregado na propaganda.

Há um capítulo reservado à histório dos anúncios. Há influência norte-ame. ricana: "Outras característicos da linguagem propagandística moderna são ligadas particularmente a profissionais americanos".
Estilo dos anúncios. Recursos estilísticos.

Uma das páginas iniciais é reservada as variadissimas firmas das quais foram solicitadas permissāo para reproduzir os anúncios de jornais, revistas, rádio, televisão, etc.

A leitura dêsse livro original além de curiosa e divertida, é muito instrutiva.

R. F. Mansur Guérios.
GUILHERMINO CESAR, O EMBUCADO DO ERVAL (MITO E POESIA DE PEDRO CANGA), Edições de FFCL do RGS, Pôrto Alegre, 1968, 1 vol. br., $12 \times 18 \mathrm{~mm}$, $120 \mathrm{pp}$.

Guilhermino Cesor, paciente e inteligente cultor da história da literatura do Rio Grande do Sul, quis dedicar um volume também ao "Capitāo (ou Major?) Pedro Muniz Fagundes, cognominado Pedro Conga), o Embuçado do Erval. Um volume, digamos assim, de feitio "volante", mas nem por isso superficial, nem desprovido de séria e rica erudiçōo, fruto de laboriosa pesquisa. Um perfil biográfico, literário e critico, em que a figura do soldado-poeta Pedro Canga quose um mito - é estudada com simpatia e valorizada literòriamente.

Eis o indice do volume:

\section{I - O Embuçado do Erral.}

1. Trovador esquecido.

2. Pedro Conga e Cezimbra Jaques.
3. Afinal, o compilador.

4. Valorizaçāo tardia.

11 - Sua obra.

1. Poesios atribuidas.

2. As emendas de Simōes Lopes Neto.

3. O sistema estrófico.

4. Perício no emprêgo dos "adynata".

5. Intemporalidade e ortesanato.

III - O Homem e Sua Humanidade.

1. Claro-escuro biográfico.

2. Entre os "Guardas Nocionais briosos".

IV - Posfácio.

Biografia de Pedro Muniz Fagundes por Manuel da Costa Medeiros.

Bibliografia.

Luígi Castagnola
MIGUÉS JOSE RODRIGUES - ONDE A NOITE SE ACABA - Lisboa, Estúdios Cor, 1968, $240 \mathrm{pp}$.

O conto, de algumas décadas para cá, vern sendo fôrma cultivadíssima na $\mathrm{Li}$ teratura Portuguêsa, por autores da maior expressão e é o caso, para apecitar alguns, de Branquinho da Fonseca, Vergilio Ferreira, Fernando Namora, Jo- sé Régio, José Cardoso Pires, Manuel da Fonseco, Sophia de Mello Breyner Andersen, Fernanda Botelho, José Rodrigues Miguéis.

José Rodrigues Miguéis, autor de Leah, Gente de Terceira Classe, no tocante a contos e de vários romances: Escola do Paraíso, Uma Aventura Inquietante, entre outros, vê reeditado por Estúdios Cor sua obra Onde a noite se acaba. 
$O$ volume insere os seguintes contos e novelas: "Enigma", "Morte de Homem", "A maneho não se se opaga", "O chapelinho vermelho", "A linho invisivel", "Cinzas de incèndio", "O acidente", "Belezo orgulhosa" e encerra-se com uma noto do autor.

A primeira impressão com que se soi destas narrativas é de estranheza da vida, cousada por um mistério que ultrapassa de longe a compreensōo que possam ter as personogens. Parece que algumas fôrças inponderóveis $e$ incompreensiveis explicam ou antes complicam os "fatos" que ocorrem no decorrer dos contos. Por outro lado, um sentido poético, mistico e trágico parecem presidir os momentos conflituosos únicos (e por isso sāo contos) que se revelam neste Onde a noite se acaba. $E^{\prime}$ o que se evidencia em narrativas como "Morte de homem", "A mancha nōo se apaga" e "Enigma".

O mistério com que J. R. M. cerco sua narrativa, consciente ou inconscientemente da porte do autor, apresenta duas virtudes ou virtualidades: primeiro, ao plano do conteúdo, por encerrar o verdade ao plano da narrativa e da vida (dai a verossimilhança), no concernente ao fantóstico e ò ficção; segundo, ao plano da técnica narrativa, porque constitui artificio validissimo poro atrair a atençāo e manter os leitores em constante "suspense". Tudo isto leva a um ospecto fàcilmente verificóvel: os cenórios ou melhor a atmosfera e a ação interessam mais que a próprio personogem e por isso lembrando a classificaçāo de contos proposta por Carl F. Grabo, podemos inseri-los num tipo: misto de atmosfera e emoção. Os mesmos contos que citomos acima ilustram bem a nossa ofirmaçāo. Nesto predominâncio do acidente, do ocontecimento, da situaçāo sôbre a personagem, revela-se a maestrio e de certo modo, a universalidade que o autor consegue conferir às suas narrativas. E é com a visão trágica e poética que J. R. M. coroa as situaçōes criadas e fulmina os seus leitores.
Num certo sentido, os contos respiram um or portuguès, mas vez ou outra comparece a atmosfera mais ampla, refletindo um cosmopolitismo que evita o estreiteza de ambientaçāo que pudesse diminuir o raio de ação do conto.

No toconte então ao enrêdo, à histório, J. R. M. realmente consegue criar êstes momentos únicos, fundamentais $e$ reveladores das personagens; mas também ao nivel do "discurso" literário, opera-se a maior parte das funçōes literaries assinaladas por Roman lacobsen. Uentre elas destaco-se evidentemente a tunçao poética ou tantóstica, em que J. K. M. Logro a supra-realidade atraves de reoçoes e momentos psicológicos de suas tersonagens, reveiando um ouiro munao poetico, misterioso, raianao as vezes o irreal; a tunçao expressıvo ou emotiva concomitantemente se depreenue ua exiroversoo da sensidilidade apuroao aas personagens que emitem seirrımentos e emoçoes derivados da estranneza, ao misterio que o "vida" provocu nas tais situaçoes granaısas e irrepetıveıs no ser. A tunçuo metoıınguistıcu ou transinguística taindem realiza-se nu Innguogem dos contos, ja que ho un. mesmo codigo entre as personagens; 4 que noo no e o entenumento ao couigu oa viaa, pois como atırmamos muitos tatos permanecem numa área sombria e indecirravel. $E^{\prime} \circ$ que ocorre na primeiro narrativa, "Enıgma" em que a personagem principal ao história adquire um pequeno cotre numa casa de antigüidades e misteriosomente isto vem causor-lhe a morte em condiçōes trágicas, embora com certo dose de humor. $E$ oqui surge outro elemento importante no processo de criação dos contos: ao lado do poético e do trágico oparecem com grande destaque a ironia, o humor, constituindo mois om atrativo a estas histórios em si já tão atraentes.

Em sintese e e monclusāo, pelo que expusemos, nāo só no tocante ao conteúdo mas também no respeitante oos expedientes técnicos, êste breve volume de contos revela-se cheio de qualidades e constitui o que de melhor tem produzido J. R. $M$.

Joäo Décio - Fac. Fil. de Marília. 
ESCARPIT, ROBERT - PARAMEMOIRES D'UN GAULOIS - Flammarion, Paris, 19568.

A Flammarion publicou no terceiro trimestre do ano passado, o último livro de Robert Escarpit, Paramémoires d'un gaulois. Considerado antes de mais nada como um humorista e sem deixar de sê-lo é também ou autor de Sainte Lysistrade (1962), Le Littératron (1964), Honorius, Pape (1967), romances que entre outras qualidades possuem a de serem excelentes documentórios do momento em que vivemos. Paramémoires d'un gaulois seaue uma trilha diferente pois éo resultado de um impulso que surge em muitos francêses, o de explicar-se. Juntamente com Montaigne, Rousseau, Gide, Simone de Beauvoir, Mauraux, Escarpit parece tornor definitivo aue o eu não é detestável. Para. mémoires d'un gaulois é o eu de EscarDit, eu cujo valor consiste em ser algo de muito representotivo do homem do século $X X$, em ser um puro francês convicto e principolmente em ser êle mesmo, Robert Escarpit, na medida em que o sinceridade é possível na obra de memórios. Será difícil encontrar noutfo escritor o interêsse que Robert Escorpit possui em relação aos objetos e situaçōes de hoje. ' $E^{\prime}$ como se êle quizesse grovar o seu momento, adegando-se parara isso à matéria ou ao espirito hodiernos. Talvez por isso falar longamente sôbre a sua caneta ou a sua máquina de escrever, fixar o gôsto dos comuns dos mortais pelas histórias patéticos, vividas, divertidos, apresentadas pelo televisão ou pelo cinema lhe seja tão importante como abordar o problema da posiçōo política ou o da aceitação das mudanças ocorridas em nossos dias. Em se tratando de mudança, de inovaçäo, de moderno, Escarpit é um entusiasta. Näo se afasta entretanto de suas raízes que êle sabe exatamente onde estão e há quanto tempo. A par desta incrivel copacidade que deve ser atóvica, de captar as diferenças entre os habitantes de Soint-Macaire e os de Toulenne, povoados seporados um do outro por dois enor- mes quilômetros, nada mais puramente francês que a sua facêta de gastrônomo. Observaçōes aqui e ali, marcam o seu conhecimento do assunto, mas realmente extraordinárias são as páginas que descrevem com vagar e mesmo religiosidade o almôço de Páscoa na casa de seus avós. Se estas páginas não estivessem assinodas, se não fôsse conhecida a nacionalidade de seu autor, o prazer e o orgulho que se desprendem da evocação das nuanças da boa mesa, bastariam para revelar que a mão que escreve é a de um francês do sul. $E$ eis que certas froses a the descreverem n físico, a sutileza de sua percepção dos perfumes e cheiros, as confissōes dos anseios de escritor, o reconhecimento de uma estagnação como universitário, uma queixa muito sentida contra pessoas de um determinado povo, algum toque de humor gaulois, outro da ironia voltariana que lhe é própria, muitas asserçōes bilhantes, vêr desenhó-lo nitidamente e fazer com que surjo inconfundivel.

\section{Cecilia Teixeira de Oliveira $* * *$}

TACCA, OSCAR. LA HISTORIA LITERARIA, Gredor, Madrid, 1968. . . . .

O senhor Oscar Tacea é professor do Literatura na Facultad de Humanidades de la Universidad Nacional del Nordeste. Seu livro é devéras oportuno pois aborda esta interessante questão que é - História literária. 0 assunto é apresentado em quatro capítulos: Cuestiones de Principio, Cuestiones de Método, Lo Historia de la Literatura Contemporónea, Arte e Historio. O primeiro capítulo responde à pergunta: é possivel fazer história de Arte e Literatura? O segundo esclarece quanto ò ordenação e à classificação do vasta produção literária. 0 terceiro se atém d̀ História contemporâneo e a seus problemas. O quarto, do questão hoje tão discutida: a maneira de entender, de aceitar, de interpretar uma obra literária. As principais qualidades do livro são o poder de sintese e a clareza na construção o que fazem déle, juntamente com o apêndice biblio- 
gráfico que apresentado no excelente sistema europeu, uma obro de fócil e útil consulta, além de constituir umo abertura de caminhos. A obra cumpre assim, aquilo que o autor pretendeu ao fazer sua uma frase de Umberto Eco: "desenvolver um problema nõo quer dizer resolvê-lo, mas pode significar um esclarecimento que permita uma discussão mais profunda".

Cecília Teixeira de Oliveira 